University of Nebraska - Lincoln

DigitalCommons@University of Nebraska - Lincoln

\title{
Construction and Testing of a Simple and Economical Soil Greenhouse Gas Automatic Sampler
}

\author{
Daniel Ginting \\ University of Nebraska-Lincoln, dginting@usgs.gov \\ Spemcer L. Arnold \\ USDA-ARS-SWCRU \\ Nicholas S. Arnold \\ NSA Consulting \\ Ronald S. Tubbs \\ USDA-ARS-SWCRU
}

Follow this and additional works at: https://digitalcommons.unl.edu/usdaarsfacpub

Part of the Agricultural Science Commons

Ginting, Daniel; Arnold, Spemcer L.; Arnold, Nicholas S.; and Tubbs, Ronald S., "Construction and Testing of a Simple and Economical Soil Greenhouse Gas Automatic Sampler" (2007). Publications from USDAARS / UNL Faculty. 513.

https://digitalcommons.unl.edu/usdaarsfacpub/513

This Article is brought to you for free and open access by the U.S. Department of Agriculture: Agricultural Research Service, Lincoln, Nebraska at DigitalCommons@University of Nebraska - Lincoln. It has been accepted for inclusion in Publications from USDA-ARS / UNL Faculty by an authorized administrator of DigitalCommons@University of Nebraska - Lincoln. 


\title{
Construction and Testing of a Simple and Economical Soil Greenhouse Gas Automatic Sampler
}

\author{
Daniel Ginting, ${ }^{1}$ Spencer L. Arnold, ${ }^{2}$ Nicholas S. Arnold, ${ }^{3}$ \\ and Ronald S. Tubbs ${ }^{4}$ \\ ${ }^{1}$ Department of Agronomy and Horticulture, University of Nebraska, \\ Lincoln, Nebraska, USA \\ ${ }^{2}$ USDA-ARS-SWCRU, Lincoln, Nebraska, USA \\ ${ }^{3}$ NSA Consulting, Lincoln, Nebraska, USA \\ ${ }^{4}$ USDA-ARS-SWCRU, Lincoln, Nebraska, USA
}

\begin{abstract}
Quantification of soil greenhouse gas emissions requires considerable sampling to account for spatial and/or temporal variation. With manual sampling, additional personnel are often not available to sample multiple sites within a narrow time interval. The objectives were to construct an automatic gas sampler and to compare the accuracy and precision of automatic versus manual sampling. The automatic sampler was tested with carbon dioxide $\left(\mathrm{CO}_{2}\right)$ fluxes that mimicked the range of $\mathrm{CO}_{2}$ fluxes during a typical corn-growing season in eastern Nebraska. Gas samples were drawn from the chamber at 0,5 , and $10 \mathrm{~min}$ manually and with the automatic sampler. The three samples drawn with the automatic sampler were transferred to pre-vacuumed vials after $1 \mathrm{~h}$; thus the samples in syringe barrels stayed connected with the increasing $\mathrm{CO}_{2}$ concentration in the chamber. The automatic sampler sustains accuracy and precision in greenhouse gas sampling while improving time efficiency and reducing labor stress.
\end{abstract}

Keywords: manual sampling, diffusion, gas analysis, vented chamber

\section{INTRODUCTION}

Resources and complex natural settings dictate the choice of sampling techniques for better capture of spatial and/or temporal fluctuation of soil greenhouse

Received 24 April 2006; accepted 27 September 2006.

Address correspondence to Daniel Ginting, U.S. Geological Survey Nebraska Water Science Center, 5231 S. 19th St., Lincoln, NE 68512-1271, USA. E-mail: dginting@usgs.gov 
gas fluxes. Whether using on-line gas analysis or off-line gas analysis system, gas flux calculation requires gas concentration measurements sequentially for a specific period of time. On-line gas analysis needs electricity (alternating current, $\mathrm{AC}$ ) to power the gas chromatograph (GC), the air sampling circulation system from gas chamber to the GC, controllers (Riddle et al., 1997; Magiotto et al., 2000; Flessa et al., 2002; Papen and Butterbach-Bahl, 1999) and many other accessories (e.g. air conditioner unit for the GC housing). In the on-line gas analysis, the distance between the GC and measurement locations is limited. Locations hundreds of meters apart need separate units of the on-line system, making this costly. Power requirement, equipment cost, logistics of analytical carrier gas for GC analysis in the fields, and distance between measurement sites make the on-line system not feasible in various circumstances.

An alternative to the on-line gas analysis is off-line analysis, where air samples are collected from the field and brought to the laboratory for analysis (Bremner et al., 1981; Lessard et al., 1996; Ginting et al., 2003). At least three samples are needed for each flux calculation (Hutchinson and Mosier, 1981). To have a larger degree of freedom in flux calculation using a regression analysis, four or more samples are recommended (Livingston and Hutchinson, 1995). If done manually, a person needs to be present at each site to draw soil gas samples. Since a person is stationary for the duration of sampling, the waiting limits the number of sites accomplished during a narrow sampling window (daylight hours). For example, a representative soil carbon dioxide $\left(\mathrm{CO}_{2}\right)$ sampling window is between 0800 to $1000 \mathrm{hr}$ and 1600 to $1800 \mathrm{hr}$ (Parkin and Kaspar, 2003). Manual sampling is also laborious; the lengthy waiting at a sampling site is tiring and may affect the consistency of samplings.

There is a need for an automatic sampler that automatically draws and stores air samples temporarily for later transfer to pre-vacuumed vials for laboratory analysis. In this case, a person is not needed to perform sequential gas sampling and thus is not bound to one site for the duration of air sampling. To be useful, the sampler must rely on little direct current (DC) power, be simple, compact, lightweight, low cost, and low maintenance.

When sampling is done manually, a person draws an air sample from the chamber with a syringe and transfers the sample to a pre-vacuumed vial immediately. Using the automatic sampler, however, the collected samples (in the syringe barrel) stay connected with the increasing gas concentration in the chamber (via sampling tube, Figure 1) until the person transfers the samples into the vials. Therefore, the main premise of the automatic sampler is that gas diffusion between the gas chamber and the samples is negligible for the period of time until samples are transferred to the vials.

The objective is to develop and test the accuracy and precision of a simple and economical soil gas sampler that allows sequential mixing and drawing of soil gases into syringes for later transfer to pre-vacuumed vials for simultaneous analysis of various soil greenhouse gases with GC in the laboratory. 


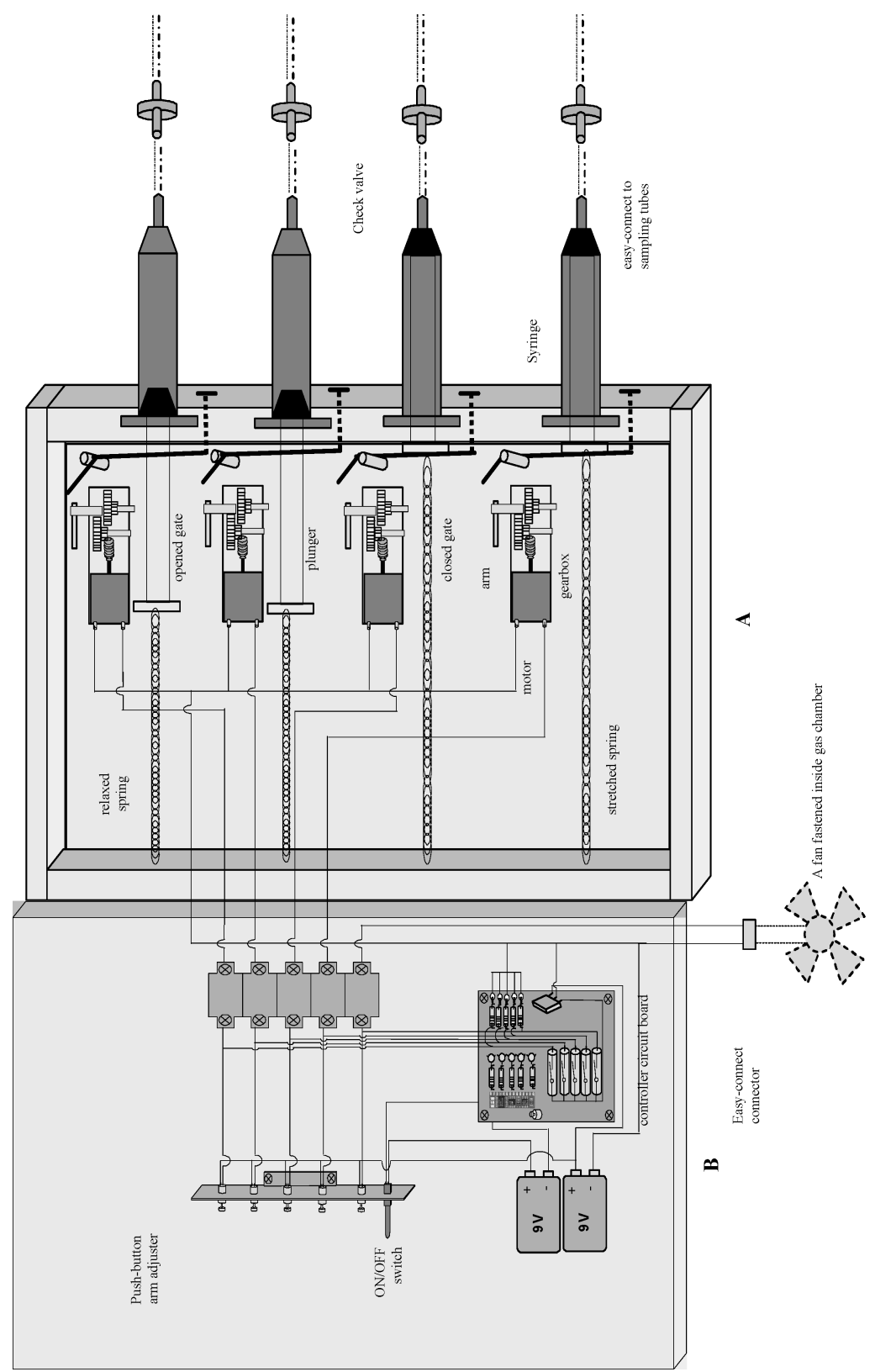

Figure 1. Layout of soil gas sampler: A) four sets of sampling devices each consisting of a worm gearbox and arm, mechanical gate, and 30-mL syringe, which is connected to a sampling tube leading to gas chamber, and B) controller circuit board, push-button gearbox arm adjuster, and power supply. 


\section{MATERIALS AND METHODS}

\section{Sampler Construction}

A simple, compact, lightweight, and low cost gas automatic sampler was designed, constructed, and tested to automatically transfer four soil gas samples sequentially to four separate syringes. The light weight $(5 \mathrm{~kg})$ and compact size (450-mm length $\times 241$-mm width $\times 90$-mm height) allows for easy carrying in the field. The automatic sampler consists of two main components: 1) sampler fastened in a Plexiglas [poly (methyl methacrylate)] box and 2) controller fastened to the box lid (Figure 1). The sampler consists of four sets of sampling devices. Each set consists of a worm-gearbox (Tamiya Inc., Shizuoka City, Japan), mechanical gate, 30-mL syringe, and spring. One end of the spring is fastened to the rear wall of the sampler box and the other end to the syringe plunger. The gearbox has a motor, gears, and rotating arm. The sole function of each gearbox is to open the gate and release the stretched spring attached to a syringe plunger. The four gearboxes are wired to the controller. Sampler and controller parts and their estimated costs are listed in Table 1.

The controller consists of two main parts: 1) electronic circuit and 2) gearbox-arm adjuster (Figure 1). The gearbox-arm adjuster functions to position the arm pointing away from the gate to allow momentum to disengage the gate. The electronic circuit consists of two $9 \mathrm{~V}$ batteries, one BS1-Basic Stamp ${ }^{{ }_{1}}$ microcontroller (Parallax Inc., Rocklin, CA), one voltage regulator, and five sets of reed relays, switch transistors, resistors, and light-emitting diodes. For further information on BS1-Basic Stamp ${ }^{\circledR}$, refer to its manual (Parallax Inc, 2000) and online resources at http://www.parallax. com/html_pages/products/basicstamps/basic_stamps.asp (verified April, 2006). The five relays are connected to the four sets of sampling devices and to a motorized fan (located in the gas chamber). One $9 \mathrm{~V}$ battery powers the Basic Stamp ${ }^{\circledR}$ microcontroller and the other one (reduced to $5 \mathrm{~V}$ by the voltage regulator) powers the sampling devices and fan when the relay is turned on by the controller. The main diagram of controller circuitry is presented in Figure 2.

The Basic Stamp ${ }^{\circledR}$ microcontroller was programmed to sequentially supply electrical current to switch on transistors that drive the relays to perform the following sequential actions:

1. Turn on the fan for 30 seconds.

2. Immediately after the fan is off, turn on gearbox 1 for 3 seconds.

3. At an interval of time after step 2, turn on the fan for 30 seconds.

4. Immediately after the fan is off, turn on gearbox 2 for 3 seconds.

\footnotetext{
${ }^{1}$ Mention of products does not constitute endorsement by the University of Nebraska or the USDA-ARS over other similar products.
} 


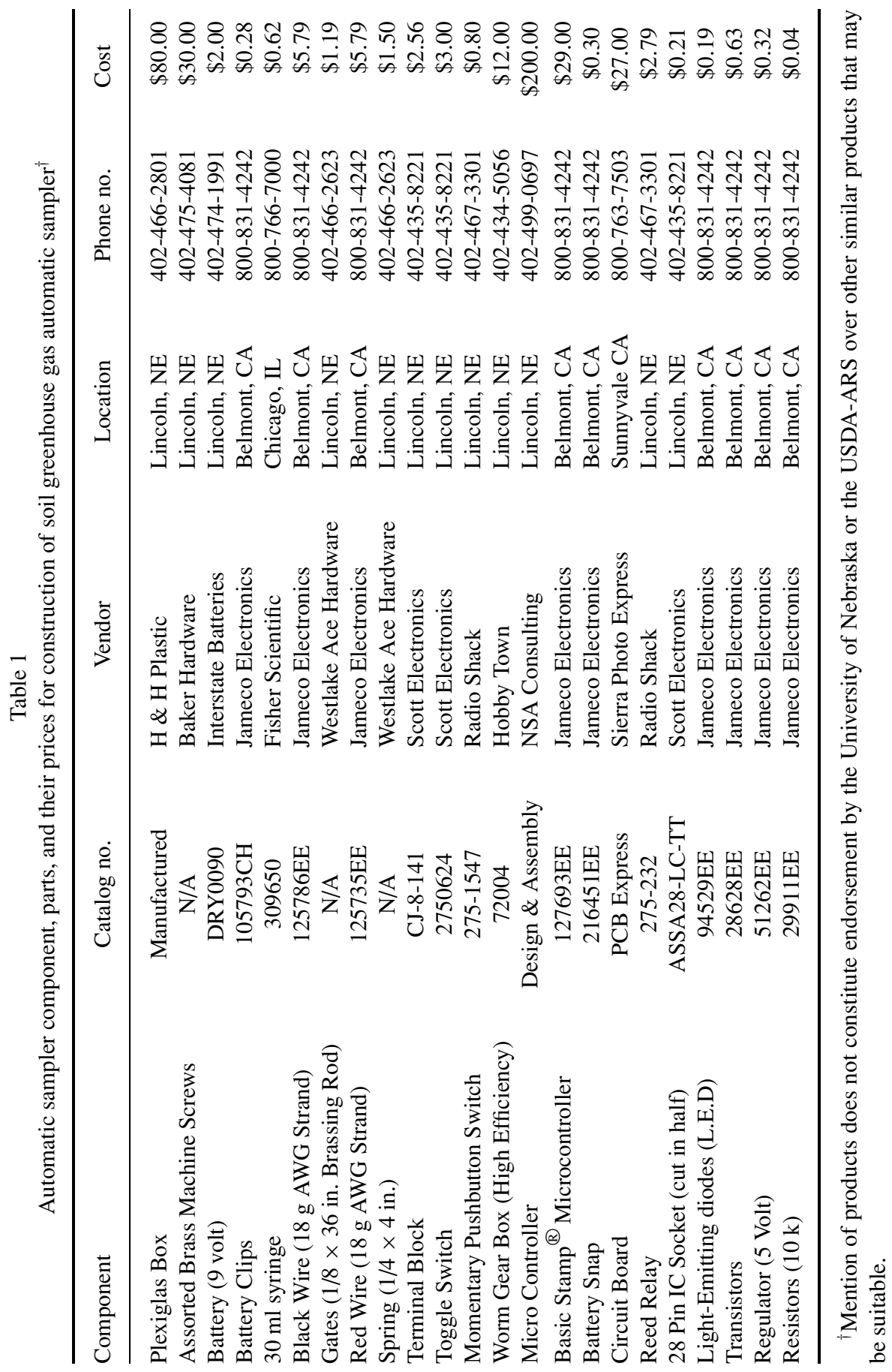




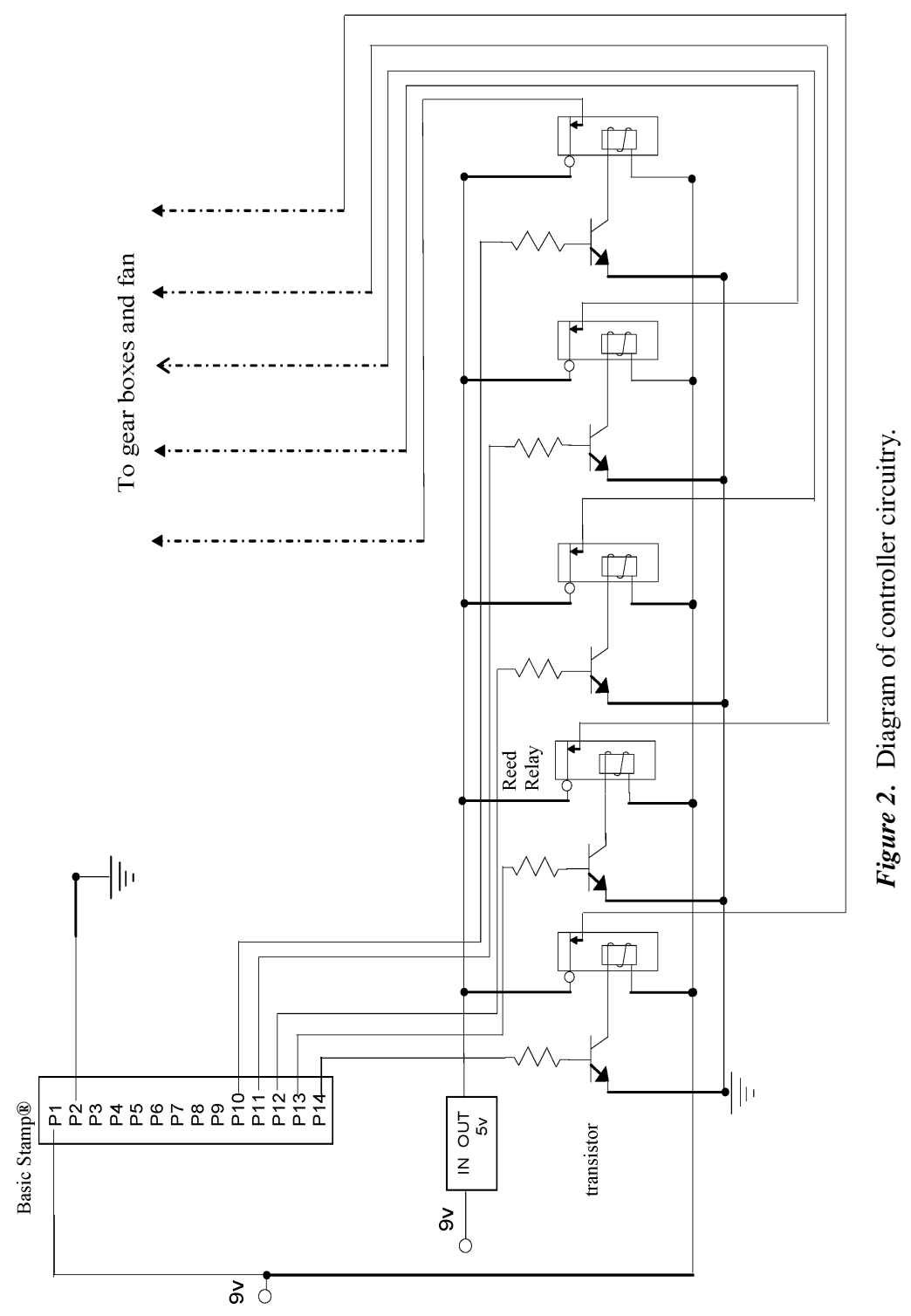


5. At an interval of time after step 4, turn on the fan for 30 seconds.

6. Immediately after the fan is off, turn on gearbox 3 for 3 seconds.

7. At an interval of time after step 6 , turn on the fan for 30 seconds.

8. Immediately after the fan is off, turn on gearbox 4 for 3 seconds.

9. End.

The length of time for fan (in step 1, 3, 5, and 7), interval between sampling (in step 3,5, and 7), and for gearbox rotation (in step 2, 4, 8, and 8) can be varied in the program. In our case the length of time for fan operation was 30 seconds and the interval between samples was $5 \mathrm{~min}$. The duration of air mixing with motorized fan depends on gas chamber volume. In our case, the 30- second air mixing was suitable for $100-\mathrm{L}$ chamber size. The gear box rotation was set for 3 seconds. When the controller turns on the gearbox for three seconds, the gearbox arm will rotate and open the gate, thus releasing the stretched spring. Three seconds is selected to allow three revolutions of gearbox arm to ensure releasing of spring. Releasing the spring tension pulls the syringe plunger and air sample into the syringe barrel. For further information on programming BS1-Basic Stamp ${ }^{\circledR}$, refer to its manual (Parallax Inc, 2000).

\section{Sampler Operations}

Open the sampler box lid and position the gearbox arm away from the gate (Figure 1). Connect the fan and the controller via an easy-connect connector. Connect each $30-\mathrm{mL}$ syringe to each sampling tube (350 $\mathrm{mm}$ long, 1.6-mm i.d.) extended from the gas chamber. The volume of each sampling tubes $(0.7 \mathrm{~mL})$ was $2.3 \%$ of syringe barrel volume. Stretch the spring to empty the syringe barrel by pushing the plunger all the way into the syringe barrel and close the gate (Figure 1). Repeat the procedure for the remaining sampling devices. Set and seal the gas chamber on its base. Switch on the sampler (Figure 1) to perform the sequential actions described above. After setting the sampler, the personnel can move to different sites to set other samplers. At a later time (e.g. after one hour), the person will return to the samplers to transfer samples from the syringe to the pre-vacuumed vials for analysis with the GC in the laboratory.

For field application, the automatic sampler is usually mounted on the vented gas chamber for easy connection to sampling tubes and motorized fan (Figure 3). A check valve is attached between each syringe and gas chamber (Figures 1 and 3) to avoid convective flow of gas from the syringe to the chamber. This is an extra step in case of an increase of gas pressure due to increase in the syringe temperature under direct sunlight between sampling and collection of sample. While pressure in the gas chamber is maintained at atmospheric level by the vent tube, increase of syringe temperature under direct sunlight could create pressure differential and convective gas flow between the syringe and 


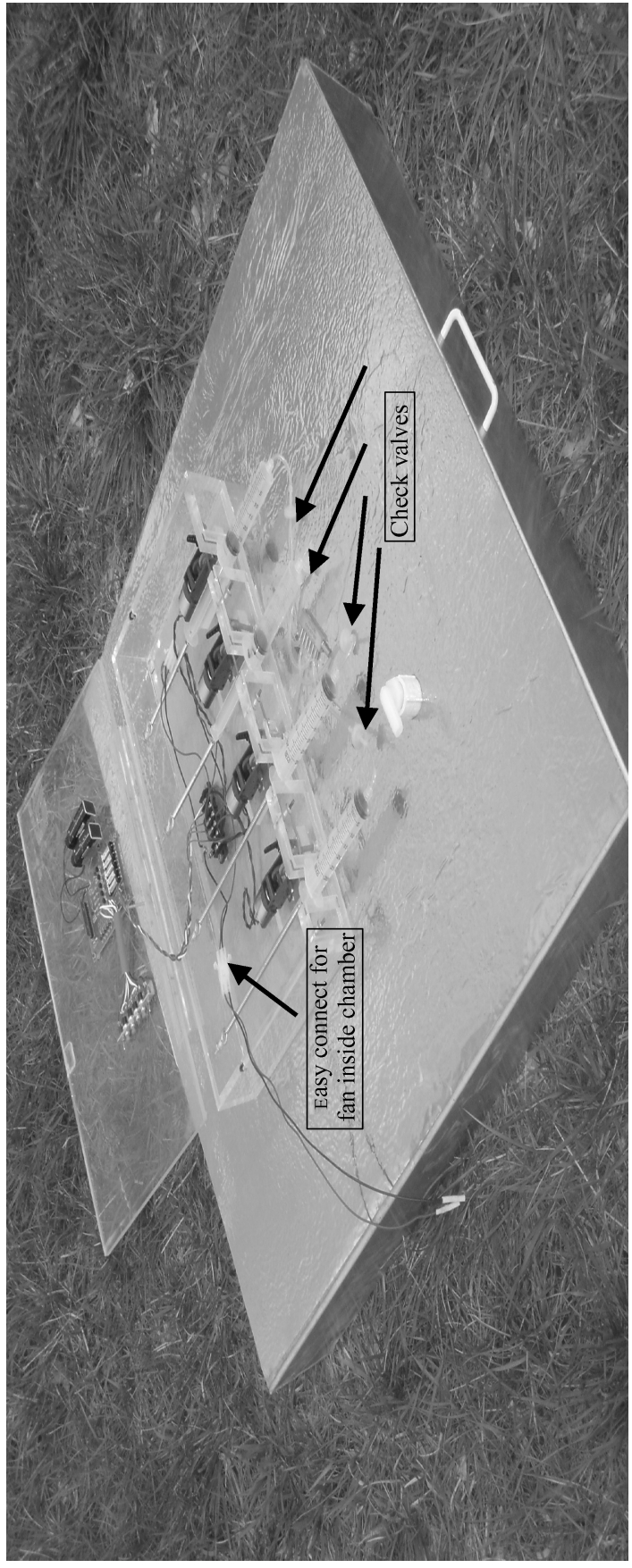

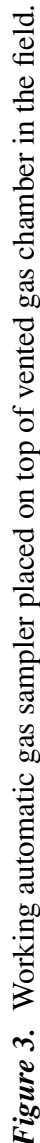


gas chamber. Since the check valve is normally-closed, the check valve would also avoid gas diffusion from the chamber to the samples in the syringe barrels.

\section{Evaluation of Accuracy and Precision in Laboratory}

The gas chamber was an aluminum ring (69-cm i.d., 7.5-cm height) welded to a vented lid as described in detail by Ginting and Eghball (2005). Its volume was $75 \mathrm{~L}$. The vent (2-mm-i.d.) on the lid is an extension of copper tube suspended horizontally under the lid. The DC electric fan $(10-\mathrm{cm}$ diameter) was fastened to the chamber inside-wall $10 \mathrm{~cm}$ beneath the lid. The four sampling tubes $(1.6$ $\mathrm{mm}$ i.d.) were inserted through a septum on the lid and lowered vertically to $10 \mathrm{~cm}$ beneath the lid. In this laboratory experiments, no check valve was used with the four sampling tubes (between the syringe and the chamber). Thus the lab experiments were done under a worse scenario of diffusion rate.

The base of the gas chamber was sealed with a plastic sheet using gray duct-tape. Two fluxes, 45 and $450 \mathrm{~kg} \mathrm{CO}_{2}-\mathrm{C} \mathrm{ha}^{-1} \mathrm{~d}^{-1}$ were tested. The $45 \mathrm{~kg}$ $\mathrm{CO}_{2}-\mathrm{C} \mathrm{ha}{ }^{-1} \mathrm{~d}^{-1}$ was a common soil $\mathrm{CO}_{2}$ flux during the growing season at an irrigated continuous corn system of the carbon sequestration project described by Ginting and Eghball (2005). The $450 \mathrm{~kg} \mathrm{CO}_{2}-\mathrm{C}$ ha ${ }^{-1} \mathrm{~d}^{-1}$ represented an extreme flux. To mimic the two fluxes, 10 and $100 \mathrm{~mL}$ of near pure $(99.8 \%)$ $\mathrm{CO}_{2}$ gas was injected into the gas chamber every $5 \mathrm{~min}$ for $1 \mathrm{~h}$. The first injection was made $2.5 \mathrm{~m}$ after sampling at $0 \mathrm{~min}$. The automatic and manual sampling drew gas samples simultaneously at 0,5 , and $10 \mathrm{~min}$.

For the manual sampling, samplings at 0,5 , and 10 min were made via the first sampling tube. A $30-\mathrm{mL}$ syringe was used to purge the sampling tube with air from the gas chamber prior to drawing a sample. Out of the $30-\mathrm{mL}$ sample drawn into the syringe barrel, $20 \mathrm{~mL}$ samples were transferred to a pre-vacuumed vial immediately. The volume of vial after capping with $20-\mathrm{mm}$ gray butyl stopper (Wheaton, Millville, NJ) was $13.5 \mathrm{~mL}$ although the vial was marketed as 10-mL amber autosampler vial (Wheaton, Millville, NJ).

The automatic sampler drew $30-\mathrm{mL}$ samples at 0,5 and $10 \mathrm{~m}$ via the second, third and the fourth sampling tubes, respectively; $20 \mathrm{~mL}$ of each sample was transferred to the pre-vacuumed vial one hour later (after $12 \mathrm{CO}_{2}$ injections were accomplished). This scenario allowed $\mathrm{CO}_{2}$ samples (in the syringe barrels) drawn at 0,5 and 10 min to stay connected (via sampling tubes) with the increasing $\mathrm{CO}_{2}$ concentration in the chamber for 60,55 , and $50 \mathrm{~min}$, respectively. The experiment was replicated three times.

The $\mathrm{CO}_{2}$ concentration in each vial was determined using the $\mathrm{GC}$ with a thermal conductivity detector maintained at $110^{\circ} \mathrm{C}$ as described by Weier et al. (1993). The average of three measurements was used to represent $\mathrm{CO}_{2}$ concentration in each vial. The rate of change of concentration within the 10 min was calculated using a linear regression model with SAS system (SAS, 2002). 


\section{Evaluation of Sampling Time Efficiency in the Field}

In a multi-year carbon sequestration project described by Verma et al. (2005), fluxes of soil $\mathrm{CO}_{2}, \mathrm{~N}_{2} \mathrm{O}$, and $\mathrm{CH}_{4}$ from three agro-ecosystems (irrigated continuous corn, and irrigated and non-irrigated corn-soybean rotations) were investigated. The three agro-ecosystems were 1 to $3 \mathrm{~km}$ apart, and within each agro-ecosystem there were seven plots 150 to $500 \mathrm{~m}$ apart. The 21 plots were to be sampled between 1000 to $1500 \mathrm{~h}$ once a week to twice a month (on average basis) year around. Based on the location of plots within each agroecosystem, the optimum route was to sample three plots per group. Therefore three automatic samplers were deployed.

\section{RESULTS AND DISCUSSION}

\section{Accuracy and Precision}

The precision of the automatic sampler was equal to the manual sampling technique. The standard errors of concentrations for samples drawn manually and with the automatic sampler were small with coefficient of variance less than $1.7 \%$. The rate of change of concentration (and thus fluxes) between the manual and automatic sampling system were also similar (Table 2).

All the concentrations fit the 1:1 line very closely for both the 45 and $450 \mathrm{~kg} \mathrm{CO}_{2}-\mathrm{C} \mathrm{ha}^{-1} \mathrm{~d}^{-1}$ (Figure 4). This observation implied that there was no difference in $\mathrm{CO}_{2}$ concentration between samples injected into the vial immediately and samples transferred one hour later. This suggested that even when check valve was not used, no diffusion occurred between the syringe barrel and gas chamber where $\mathrm{CO}_{2}$ concentration continuously increased every $5 \mathrm{~m}$ for $60 \mathrm{~min}$.

The choice of sampling tube size (length and internal diameter) is critical for the accuracy of the automatic sampler for three reasons. First, sampling tube volume should be much smaller compared to the volume of the syringe

Table 2

Known rate of change of $\mathrm{CO}_{2}$ concentration compared to those derived from samples collected manually and with automatic sampler. Values in parenthesis are standard error $(\mathrm{n}=3)$.

\begin{tabular}{lccc}
\hline Injected $\mathrm{CO}_{2}$ & Known & Manual & Sampling-aid \\
\hline $\mathrm{mL}$ per $5 \mathrm{~m}$ & & ppm (v/v) m & \\
10 & $27.4(0.56)$ & $24.3(0.93)$ & $25.3(0.55)$ \\
100 & $274(6.66)$ & $277(11.3)$ & $283(7.21)$ \\
\hline
\end{tabular}




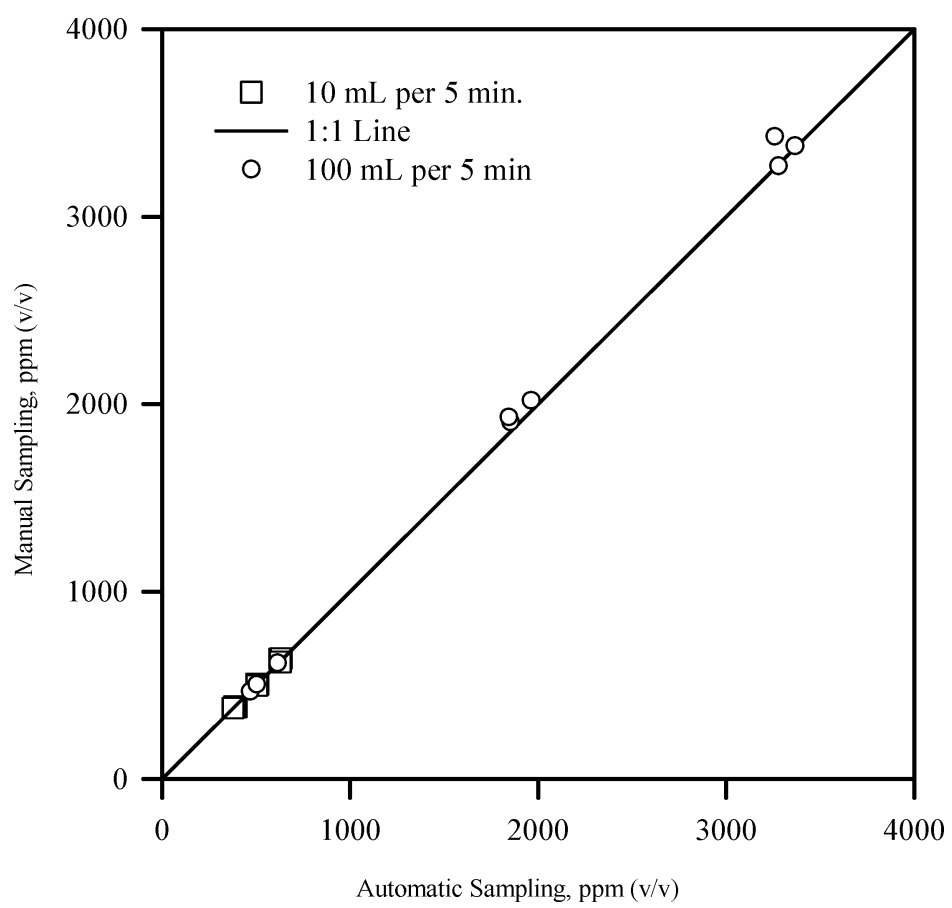

Figure 4. Comparison of $\mathrm{CO}_{2}$ concentration of samples collected manually vs. with automatic sampler at 0,5 , and $10 \mathrm{~m}$ after injections of 10 and $100 \mathrm{~mL}$ of $99.8 \% \mathrm{CO}_{2}$ into the chamber. Vertical and horizontal standard error bars of the means $(n=3)$ were negligible and thus not visible in the figure.

barrel. This will allow negligible effects of the small amount of residual gas in the sampling tube. Second, the sampling tube should not be too small for fast drawing of the gas sample when the gate was opened (Figure 1). Third, gas diffusion into/from the syringe barrel should be less than the precision of the GC. In our case, long $(350 \mathrm{~mm})$ and small $(1.6 \mathrm{~mm}$ i.d.) sampling tubes met all the three conditions.

A slightly larger tube $(2.0 \mathrm{~mm}$ i.d.) would also have resulted in negligible diffusion. As an example, on average basis, $\mathrm{CO}_{2}$ concentration in the chamber decreases $598 \mathrm{ppm} \mathrm{CO}_{2}$ (from $2058 \mathrm{ppm}$ to $1460 \mathrm{ppm}$ ) within $24 \mathrm{~h}$. The decrease equates to $25 \mathrm{ppm}$ per hour due to diffusion from the chamber (via the $320 \mathrm{~mm}$ long, 2-mm i.d. copper-tube vent) to the laboratory atmosphere (380 $\mathrm{ppm} \mathrm{CO}_{2}$ ). This diffusion rate occurred due to an unrealistically large concentration gradient between laboratory atmosphere and the gas chamber. At a lower concentration gradient, which reflects a more realistic concentration gradient between laboratory atmosphere and gas chamber, the diffusion rate via the vent tube was small. Our experiment indicated that diffusion of ambient atmospheric 
$\mathrm{CO}_{2}\left(380 \mathrm{ppm}\right.$ ) into a $\mathrm{CO}_{2}$-free gas chamber (previously flushed with helium gas) was low. Concentration in the gas chamber increased $141 \mathrm{ppm}$ in $24 \mathrm{~h}$ (5.9 ppm per hour), which was smaller than the precision of our GC system. Therefore, for a larger sampling tube and for an extremely high concentration gradient (between sample and chamber), we recommended to use the check valve with the sampling tubes.

\section{Sampling Time Efficiency}

The automatic samplers saved considerable time. The length of time needed to set up an automatic sampling system and to transfer gas samples from the syringes to pre-vacuumed vials was less than three minutes. Based on 15$\mathrm{m}$ sampling duration, two persons needed five hours (included walking time between plots and driving between agro-ecosystems) to accomplish sampling the 21 sites manually. A similar length of time was needed by one person when the three automatic samplers were used.

Automatic samplers could also reduce cost of operation in a multi-year project. The estimated cost of constructing one automatic sampler was approximately $\$ 1000$. Maintenance cost is very low (mainly periodic replacement of batteries and replacement of syringe plunger-rubber and barrel). Using $\$ 8.50$ per hour for an assistant ( $\$ 60$ per sampling trip), the cost of three automatic samplers was approximately equivalent to 50 sampling trips, or the cost of an hourly assistant in the first 1.5 years of the project.

Other benefits of using the automatic sampler were sampling consistency and reduction of personnel fatigue. Waiting and watching the clock to the second under unfavorable field conditions (e.g. under hot and humid growing corn or cold winter conditions) produced fatigue that could compromise sampling consistency and thus flux accuracy.

\section{CONCLUSIONS}

Gas concentrations and fluxes determined from samples drawn manually and with automatic sampler were similar. The economical, compact, lightweight, and low maintenance automatic sampler reduced sampling time by $50 \%$ (compared to the manual technique) in the field. This study concludes that the soil greenhouse gas automatic sampler sustains accuracy and precision for soil greenhouse gas sampling while improves time efficiency and reduces labor stress.

\section{ACKNOWLEDGMENTS}

The authors would like to thank Mr. Chris Bauer, the late Dr. Bahman Eghball at the USDA-ARS Lincoln, NE, and the student assistants (Sonny Fankhouser, 
Adam O'Neil, and Aaron Bereuter) for their assistance in soil gas sampling. We also thank the carbon sequestration program team at the University of Nebraska, Lincoln. Development of the automatic soil gas sampler was supported by the U.S. Department of Energy: a) EPSCoR program, Grant No. DE-FG-0200ER45827 and b) Office of Science, Biological and Environmental Research Program (BER), Grant No. DE-FG02-03ER63639.

\section{REFERENCES}

Bremner, J. M., G. A. Breitenbeck, and A. M. Blackmer. 1981. Effect of anhydrous ammonia fertilization on emission of nitrous oxide from soils. $J$. Environ. Qual. 10: 77-80.

Flessa, H., R. Ruser, R. Schilling, N. Loftfield, J. C. Munch, E. A. Kaiser, and F. Beese. 2002. $\mathrm{N}_{2} \mathrm{O}$ and $\mathrm{CH}_{4}$ fluxes in potato fields: automated measurement, management effects and temporal variation. Geoderma 105: 307-325.

Ginting, D., A. Kessavalou, B. Eghball, and J. W. Doran. 2003. Greenhouse gas emissions and soil indicators four years after manure and compost applications. J. Environ. Qual. 32: 23-32.

Ginting, D., and B. Eghball. 2005. Nitrous oxide emission from no-till irrigated corn: temporal fluctuation and wheel traffic effects. Soil Sci. Soc. Am. J 69: 915-924.

Hutchinson, G. L., and A. R. Mosier. 1981. Improved soil cover method for field measurement of nitrous oxide fluxes. Soil Sci. Soc. Am. J. 45: 311-316.

Lessard, R., P. Rochette, E. G. Gregorich, E. Pattey, and R. L. Desjardins. 1996. Nitrous oxide fluxes from manure-amended soil under maize. J. Environ. Qual. 25: 1371-1377.

Livingston, G. P. and G. L. Hutchinson. 1995. Enclosure-based measurement of trace gas exchange. Application and sources of error. In. P. A. Matson and R. C. Harris (eds.) Biogenic Trace Gasses: Measuring emissions from soil and water. Methods in Ecology. pp. 14-51. Blackwell Science Cambridge University Press, London.

Magiotto, S. R., J. A. Webb, C. Wagner-Ridle, and G. W. Thurtell. 2000. Nitrous and nitrogen oxide emissions from turf grass receiving different forms of nitrogen fertilizer. J. Environ. Qual. 29: 621-630.

Papen, H., and K. Butterbach-Bahl. 1999. A 3-yr continuous record of nitrogen trace gas fluxes from untreated and limed soil of an N-saturated spruce and beech forest ecosystem in Germany. J. Geophysical Res. 104: 1848718503.

Parallax Inc. 2000. Basic Stamp ${ }^{\circledR}$ Programming Manual. Version 2.0b (available at http://www.parallax.com/html_pages/downloads/basicstamps/ documentation_basic_stamp.asp, accessed April 2006). Parallax Inc., Rocklin, CA. 
Parkin, T. B., and T. C. Kaspar. 2003. Temperature controls on diurnal carbon dioxide flux: Implications for estimating soil carbon loss. Soil Sci. Soc. Am. J. 67: 1763-1772.

Riddle, C. W., G. W. Thurtell, G. K. Kidd, E. G. Beauchamp, and R. Sweetman. 1997. Estimates of nitrous oxide emissions from agricultural fields over 28 months. Can. J. Soil Sci. 77: 135-144.

SAS Institute. 2002. The SAS System for Windows 9.0. SAS Inst., Cary, NC.

Verma, S. B., A. Dobermann, K. G. Cassman, D. T. Walters, J. M. Knops, T. J. Arkebauer, A. E. Suyker, G. G. Burba, B. Amos, H. Yang, D. Ginting, K. G. Hubbard, A. A. Gitelson, and E. A. Walter-Shea. 2005. Annual carbon dioxide exchange in irrigated and rainfed maize-based agroecosystems. Agricultural and Forest Meteorology 131: 77-96.

Weier, K. L., J. W. Doran, J. F. Power, and D. T. Walter. 1993. Denitrification and the dinitrogen/nitrous oxide ratio as affected by soil water, available carbon, and nitrate. Soil Sci. Soc. Am. J. 57: 66-72. 